\title{
Quantifying metamorphopsia with M-CHARTS in patients with idiopathic macular hole
}

\author{
This article was published in the following Dove Press journal: \\ Clinical Ophthalmology \\ 20 September 2017 \\ Number of times this article has been viewed
}

lori Wada

Shigeo Yoshida

Yoshiyuki Kobayashi

Yedi Zhou

Keijiro Ishikawa

Shintaro Nakao

Toshio Hisatomi

Yasuhiro Ikeda

Tatsuro Ishibashi

Koh-hei Sonoda

Department of Ophthalmology, Kyushu University Graduate School of Medical Sciences, Fukuoka, Japan

Correspondence: Shigeo Yoshida Department of Ophthalmology, Kyushu University Graduate School of Medical Sciences, 3-I-I Maidashi, Higashi-ku,

Fukuoka 8I2-0054, Japan

$\mathrm{Tel}+8 \mid 926425648$

Fax +8I 926425663

Email yosida@med.kyushu-u.ac.jp
Purpose: The purpose of this study was to determine the degree of metamorphopsia using M-CHARTS ${ }^{\mathrm{TM}}$ in patients with idiopathic macular hole before and after pars plana vitrectomy and internal limiting membrane (ILM) peeling.

Patients and methods: The records of 22 eyes of 22 patients with a full-thickness macular hole who underwent pars plana vitrectomy and ILM peeling were reviewed. All patients underwent a complete ophthalmic examination including spectral-domain optical coherence tomography (OCT). Horizontal metamorphopsia (MH) and vertical metamorphopsia (MV) scores were determined using M-CHARTS at the same time. The time course of changes in metamorphopsia and the relationship between best-corrected visual acuity (BCVA) and OCT parameters were assessed.

Results: Sealing of the macular hole was noted in all eyes after surgery. BCVA improved significantly from 1 month after surgery $(P<0.001)$. The MV score was significantly higher than the MH score before surgery $(P<0.05)$ and improved significantly from 1 month after surgery $(P<0.03)$. The MH score improved significantly at 6 months after surgery $(P<0.001)$. The postoperative MV and MH scores became closer to one another from 1 month after surgery. Moreover, the MV score was higher than the MH score at all postoperative assessments. There was a significant correlation between the MV and MH scores at all follow-up assessments. There was no significant correlation between BCVA and the MV or MH score at any follow-up assessment.

Conclusion: The satisfaction of the patients with macular hole after surgery cannot be necessarily measured by BCVA alone, because M-scores were not correlated to BCVA in postoperative evaluation. Therefore, evaluation of the MV and MH scores can be an independent treatment outcome in addition to BCVA.

Keywords: macular hole, metamorphopsia, optical coherence tomography

\section{Introduction}

Macular hole is a disease that results in a hole in the fovea and is caused by tangential traction on the fovea by the prefoveal vitreous cortex. ${ }^{1}$ During formation of a macular hole, localized circular displacement toward a more peripheral location occurs at a point around or near the center of the fovea. The condition predominantly affects women older than 60 years.

First described in 1991 by Kelly et al, ${ }^{2}$ surgery is the most effective therapeutic intervention for macular hole and has been widely used to treat the disease. The anatomic success rates of surgery and its visual outcomes continue to improve with the development of surgical procedure. ${ }^{3-6}$ Furthermore, the inverted internal limiting membrane (ILM) flap technique is now a popular procedure for large macular holes with brilliant blue $\mathrm{G}(\mathrm{BBG}) .^{7}$ Almost all patients with a macular hole who undergo surgery have 
improved visual acuity. However, vision loss is not the only manifestation of macular hole. These patients are also likely to develop visual field defect, scotoma and metamorphopsia. ${ }^{5-8}$ Metamorphopsia in particular should also be evaluated postoperatively in patients with a macular hole.

Several studies have reported finding metamorphopsia in patients with macular disease. Amsler charts are often used to evaluate metamorphopsia in patients with several macular diseases, including macular hole. ${ }^{9-16}$ However, it is difficult to quantify the severity of metamorphopsia using these charts. Therefore, another more specific chart (M-CHARTS Inami \& Co., Ltd., Tokyo, Japan) has been developed to quantify metamorphopsia. ${ }^{17}$ Using M-CHARTS, the degrees of vertical metamorphopsia (MV) and horizontal metamorphopsia $(\mathrm{MH})$ can be quantified in patients with several macular diseases more than in Amsler charts. ${ }^{17-25}$

The aim of this study was to quantify metamorphopsia in the vertical and horizontal directions separately in patients with a macular hole using the type 2 M-CHARTS. The significance of quantifying metamorphopsia in the two directions is discussed.

\section{Patients and methods}

The study included 22 eyes of 22 patients (six males and 16 females, mean age $64 \pm 1.5$ years) with a unilateral fullthickness macular hole treated surgically and followed up for 6 months at the Kyushu University Hospital between June 2012 and May 2014. Each eye underwent pars plana vitrectomy and ILM peeling with BBG and SF6 gas tamponade. The area of removal of the ILM was intended to be three disks diameter surrounding the macular hole. The study was approved by the institutional review board of the Kyushu University Hospital, and the protocol was performed in accordance with the Declaration of Helsinki for research involving human subjects. Written informed consent was obtained from all patients.

Each subject underwent a complete ophthalmic examination preoperatively, which included best-corrected visual acuity (BCVA), slit-lamp biomicroscopy, applanation tonometry, dilated funduscopy, fundus photography, and highdefinition optical coherence tomography (OCT; Cirrus ${ }^{\mathrm{TM}}$ HD-OCT 4000; Carl Zeiss Meditec AG, Jena, Germany). The inclusion criteria were as follows: presence of a macular hole, corrected visual acuity of $>1.0$ logarithm of the minimum angle of resolution ( $\log$ MAR), a pupil diameter of $>3.0 \mathrm{~mm}$, intraocular pressure of $<21 \mathrm{mmHg}$, no systemic disease likely to affect visual function, and no ocular media opacity attributable to severe cataract or vitreous hemorrhage. All ophthalmic examinations were performed before and 1,3 , and 6 months after surgery. BCVA was measured using the Landolt chart and expressed as $\log$ MAR.

M-CHARTS includes two types of metamorphopsia charts, a one-line type (type 1) and a two-line type (type 2). The type 1 M-CHARTS uses a single dotted line and is designed for patients with a fixation point such as epiretinal membrane or age-related macular degeneration, whereas the type 2 M-CHARTS uses a double dotted line and is designed for patients with a typical macular hole and avoids the influence of a central scotoma. Therefore, we used the type 2 M-CHARTS for patients with a macular hole in this study (Figure 1).

The type 2 M-CHARTS consists of 19 dotted lines with dot intervals ranging from $0.2^{\circ}$ to $2.0^{\circ}$ of visual angle. Patients with metamorphopsia caused by a macular hole will recognize a straight line projected onto the retina as an irregular or curved line. We used this version of M-CHARTS to quantify the severity of metamorphopsia in accordance with the method proposed by Arimura et al. ${ }^{9}$ First, two vertical parallel straight lines $\left(0^{\circ}\right)$ were shown to the patient. If the patient recognized the straight lines as straight, the metamorphopsia score was 0 . If the patient perceived the straight lines as irregular or curved, subsequent pages of M-CHARTS, in which the intervals between dots on the dotted lines changed from fine to coarse, were shown sequentially. When the patient recognized a dotted line as being straight, the visual angle that separated the dots was considered to represent his/ her MV score. Next, the M-CHARTS were rotated $90^{\circ}$ and the same test was carried out using horizontal parallel lines to obtain the MH score. The examinations were repeated three times for each subject to evaluate the reproducibility of the test. The examination was performed at $30 \mathrm{~cm}$, and the refraction of the eye was corrected exactly for this distance.

OCT images were used for the diagnosis of the macular hole. Based on the images obtained with OCT, we measured the minimum and base diameters of the macular hole, the average angle of the base of the macular hole, and the fluid cuff (the margin of the diameters between the minimum and base; Figure 2) before and after surgery.

\section{Statistical analysis}

All statistical analyses were performed using JMP Pro version 12.0 software (SAS Institute Inc., Cary, NC, USA). The statistical significance of differences in BCVA, MH score, 

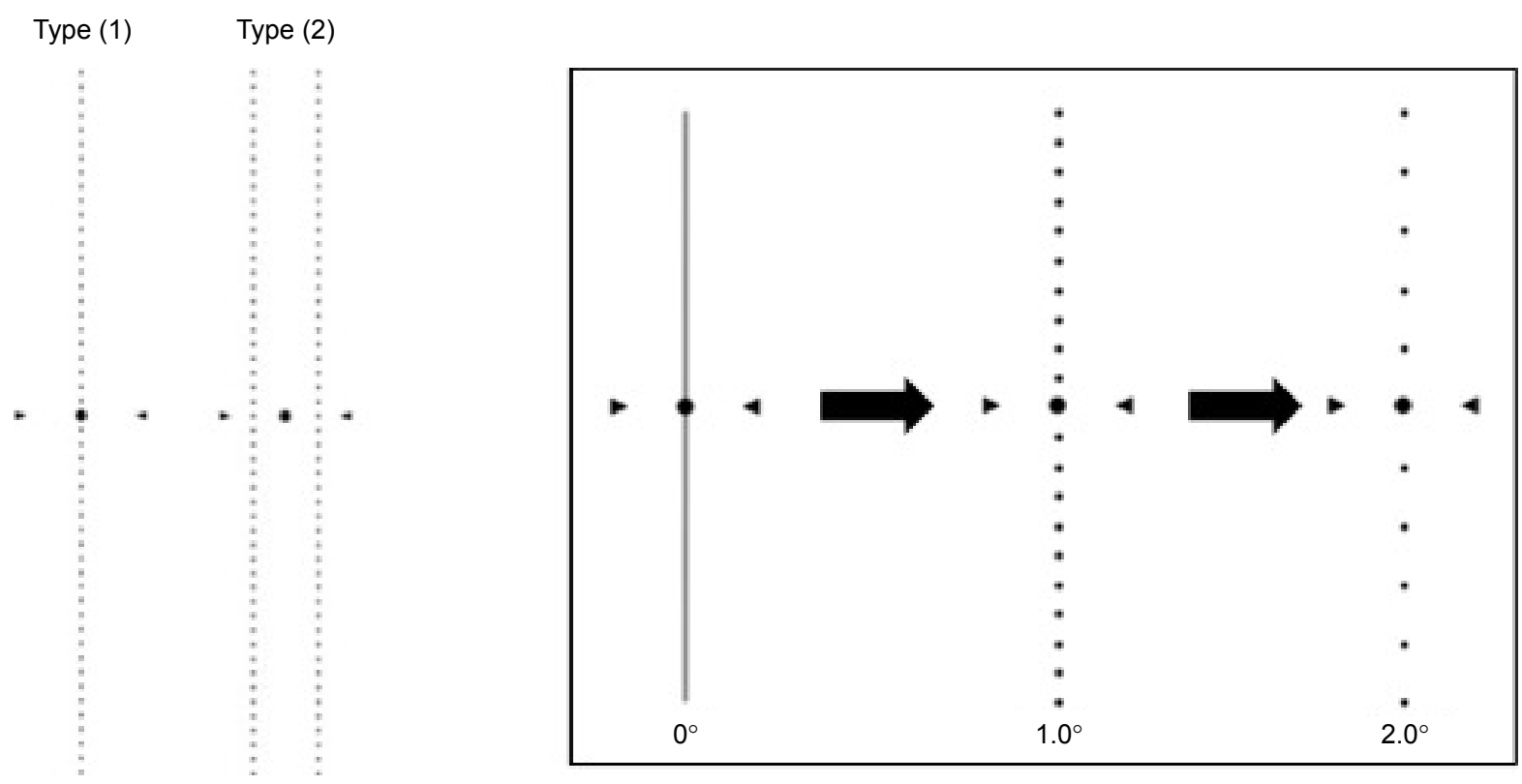

Figure I M-CHARTSTM (Inami \& Co., Ltd., Tokyo, Japan) has 19 charts and two types: one dotted line for patients with general macular disease (type I) and two dotted lines for patients with a macular hole (type 2).

Notes: The visual angle denoting the dot interval of the line seen as straight is used as the patient's M-CHARTS score. Scores were obtained for vertical and horizontal tests separately.

and MV score at two existence were determined using the Wilcoxon signed-rank test. The $\mathrm{MH}$ and MV scores at the same time were also compared using the Wilcoxon signed-rank test. The Spearman rank correlation coefficient was used to identify correlations between the preoperative BCVA; BCVA at 1, 3 , and 6 months; changes in BCVA; preoperative metamorphopsia score; metamorphopsia score at 1,3 , and 6 months after surgery; changes in the metamorphopsia score; and preoperative OCT parameters. The data are shown as the mean standard deviation unless otherwise indicated. A $P$-value $<0.05$ was considered to be statistically significant.

\begin{tabular}{|l|}
\hline$a:$ Minimum diameters \\
$b:$ Base diameters \\
$c:$ Average angle \\
$(\tan c=(b-a) / 2 d)$ \\
$b-a:$ Fluid cuff
\end{tabular}

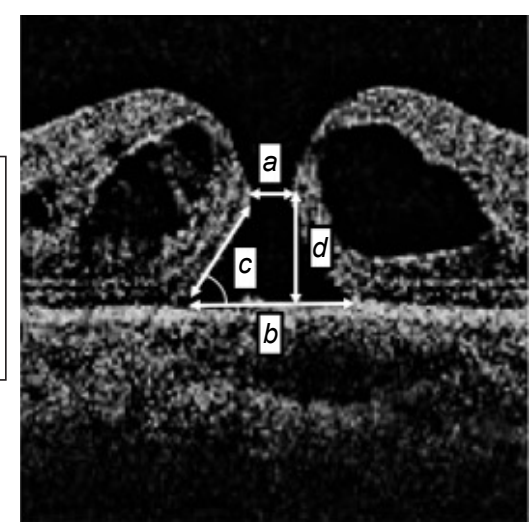

Figure 2 Minimum ( $a$ ) and base (b) diameters of the macular hole, the average angle of the macular hole $(c)$, and the fluid cuff $(b-a)$ were measured preoperatively on OCT images.

Abbreviation: OCT, optical coherence tomography.

\section{Results}

\section{Visual acuity}

Mean BCVA improved significantly from $0.65 \pm 0.27$ $\log$ MAR before surgery to $0.31 \pm 0.20 \log$ MAR at 1 month after surgery and continued to improve significantly to $0.20 \pm 0.21 \log$ MAR at 6 months after surgery $(P<0.001$, Wilcoxon signed-rank test; Figure 3).

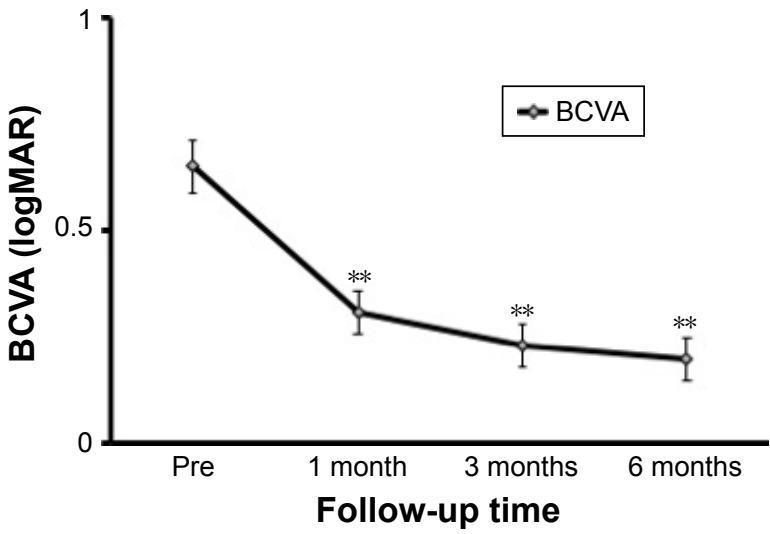

Figure 3 Time course of logMAR BCVA (mean and standard deviation) in patients after macular hole surgery.

Notes: BCVA improved significantly from $0.65 \pm 0.27 \log M A R$ before surgery to $0.3 \mathrm{I} \pm 0.20 \mathrm{log} M A R$ at $I$ month after surgery and continued to improve significantly to $0.23 \pm 0.20 \log M A R$ at 3 months and $0.20 \pm 0.21 \log M A R$ at 6 months after surgery. $* * P<0.00$ I, Wilcoxon rank-sum test. The bars indicate the mean \pm standard error of the mean.

Abbreviations: logMAR, logarithm of the minimum angle of resolution; BCVA, best-corrected visual acuity. 


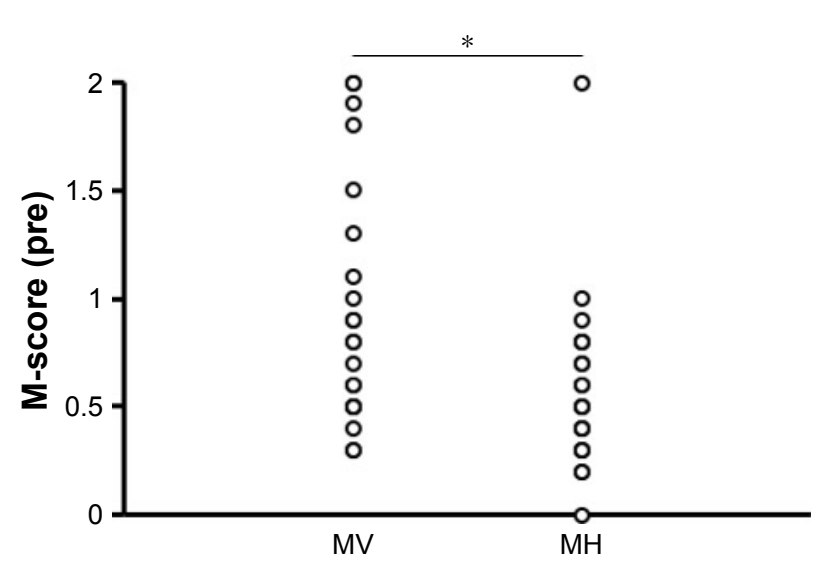

Figure 4 Comparison of preoperative scores for $\mathrm{MV}$ and $\mathrm{MH}$.

Notes: The preoperative MV score is significantly larger than the $\mathrm{MH}$ score. $* P<0.05$, Wilcoxon rank-sum test.

Abbreviations: MV, vertical metamorphopsia; $\mathrm{MH}$, horizontal metamorphopsia.

\section{Preoperative MV and $\mathrm{MH}$ scores}

The preoperative MV score was significantly higher than the MH score $(P<0.05$, Wilcoxon rank sum test; Figure 4$)$.

\section{Postoperative MV and $\mathrm{MH}$ scores}

The MV score improved significantly from $0.95 \pm 0.55$ before surgery to $0.62 \pm 0.48$ at 1 month after surgery and continued to improve significantly to $0.46 \pm 0.39$ at 6 months $(P<0.001$, Wilcoxon rank sum test; Figure 5A). The MH score improved significantly from $0.58 \pm 0.40$ before surgery to $0.36 \pm 0.44$ at 6 months after surgery $(P<0.001$, Wilcoxon rank sum test; Figure 5B).

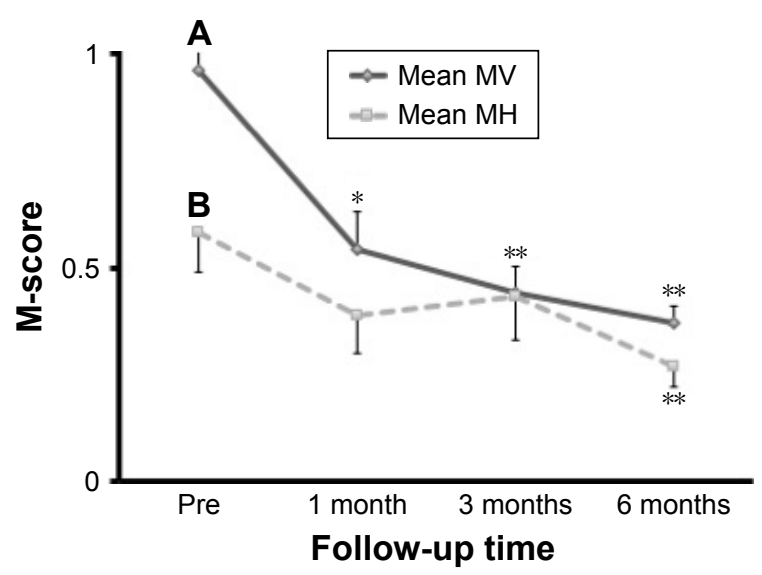

Figure 5 Time course of $\mathrm{MV}$ and $\mathrm{MH}$ scores in patients after macular hole surgery.

Notes: (A) The MV score (mean and standard deviation) improved significantly from $0.95 \pm 0.55$ before surgery to $0.62 \pm 0.48$ at I month after surgery $(P<0.00 \mathrm{I})$ and continued to improve significantly to $0.5 \mathrm{I} \pm 0.43$ at 3 months and $0.46 \pm 0.39$ at 6 months after surgery $(P<0.00 \mathrm{I})$. (B) The MH score improved significantly from $0.58 \pm 0.40$ before surgery to $0.36 \pm 0.44$ at 6 months after surgery $(P<0.001)$. $* P<0.05$ and $* * P<0.001$, Wilcoxon rank-sum test. Bars indicate the mean \pm standard error of the mean.

Abbreviations: $\mathrm{MV}$, vertical metamorphopsia; $\mathrm{MH}$, horizontal metamorphopsia.

\section{Changes in postoperative MV and $\mathrm{MH}$ scores over time}

Figure 6 shows the relationship between the MV and MH scores during follow-up. There was a significant correlation between the MV and MH scores at all assessment times ( $r=0.54, P<0.05$ before surgery; $r=0.54, P<0.05$ at 1 month; $r=0.79, P<0.001$ at 3 months; $r=0.69, P<0.001$ at 6 months; Spearman rank correlation coefficient). Although the mean MV score was higher than the mean MH score at all assessments after surgery, the difference between the two scores was not statistically significant postoperatively.

\section{Relationship between visual acuity and $\mathrm{MV}$ and $\mathrm{MH}$ scores}

There was no significant correlation between BCVA and the MV and MH scores at any assessment time (Table 1).

\section{Relationship between MV and MH scores and preoperative OCT parameters}

Next, we quantified preoperative OCT parameters (the vertical and horizontal minimum and base diameters of the macular hole, the average angle of the base of the macular hole and the fluid cuff) and the MV and MH scores using M-CHARTS at each assessment to determine the relationship between these scores and the preoperative OCT parameters. There were no significant correlations between the MV and $\mathrm{MH}$ scores and any of the preoperative OCT parameters at any assessment time (Table S1).

\section{Discussion}

Metamorphopsia has been quantified by M-CHARTS in patients with a macular hole in several previous studies. ${ }^{9,24,25}$ However, in these studies, the average of the MV and $\mathrm{MH}$ scores were used rather than the individual scores for each component. ${ }^{9,24}$

A previous study reported that the $\mathrm{M}$-score (the average of the MV and MH scores) improved from 1 month after surgery. ${ }^{24}$ However, on dividing the M-score into the two directions (vertical and horizontal), we detected improvement in the MV and MH scores at different postoperative time points, ie, significant improvement in the MV score at 1 month and in the MH score at 6 months after surgery.

Furthermore, the MV scores were consistently higher than the corresponding MH scores at all assessment times, although the difference was not statistically significant except for the preoperative assessment. Moreover, the postoperative MV and MH scores became closer to one another over time. This is probably because the preoperative MV score was higher than the MH score, resulting in different degrees 

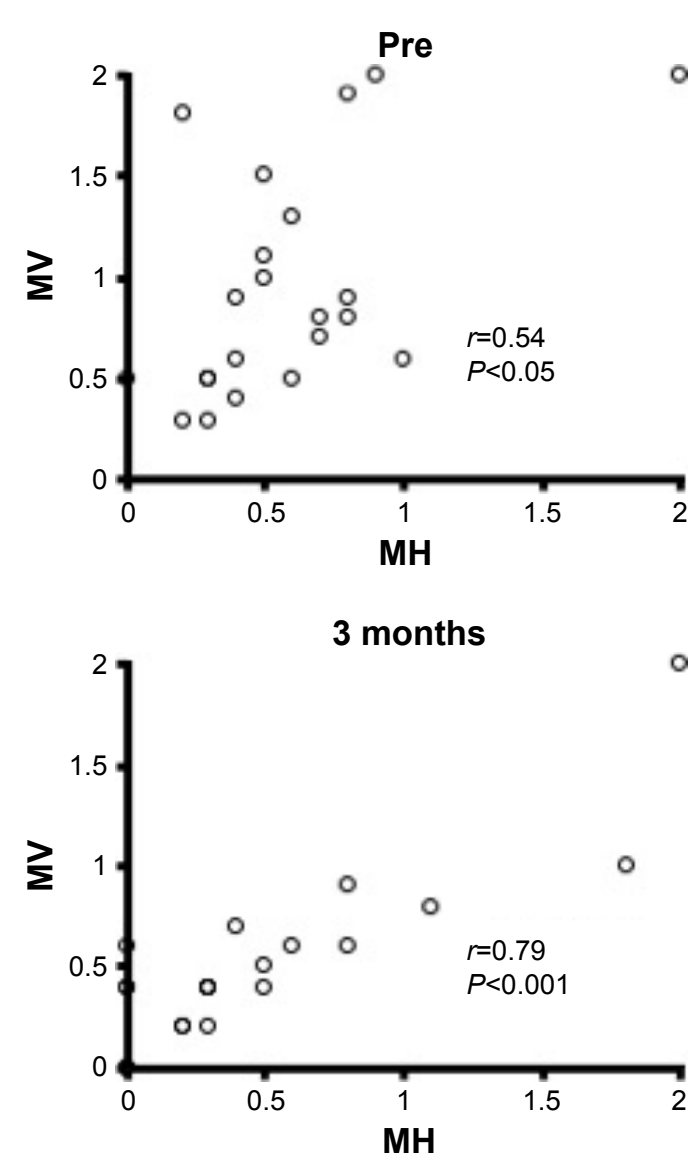

1 month

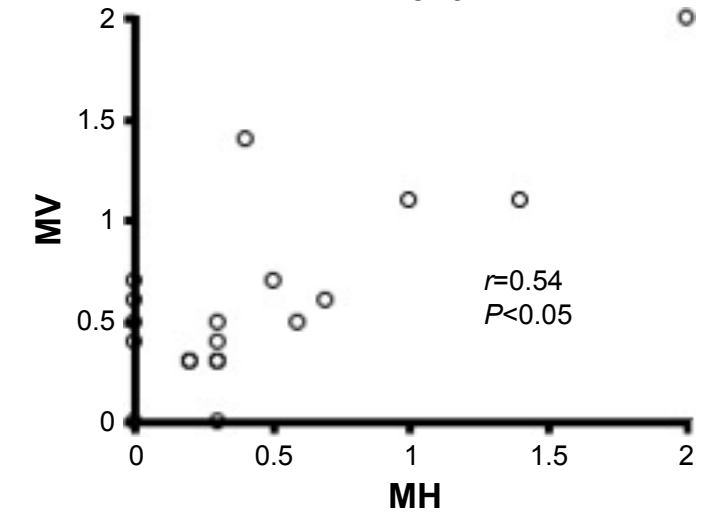

6 months

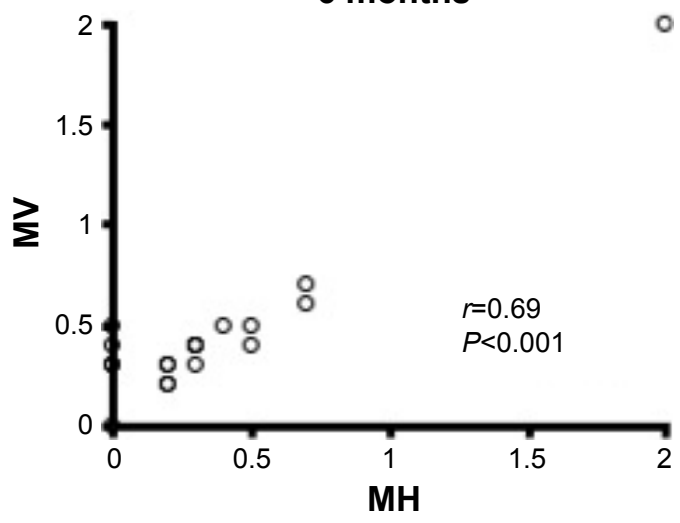

Figure 6 The relationship between the MV and MH scores after macular hole surgery at each postoperative assessment.

Notes: At all observation times, there is a significant correlation between the $\mathrm{MV}$ score and the $\mathrm{MH}$ score $(r=0.54, P<0.05$ before surgery; $r=0.54, P<0.05$ at I month; $r=0.79$, $P<0.00 \mathrm{I}$ at 3 months; $r=0.69, P<0.00 \mathrm{I}$ at 6 months; Spearman rank correlation coefficient).

Abbreviations: $\mathrm{MV}$, vertical metamorphopsia; $\mathrm{MH}$, horizontal metamorphopsia.

of improvement between the two scores. This might also be the reason why the MV score recovered more quickly (from 1 month after surgery) than the MH score (at 6 months after surgery).

Table I Relationship between BCVA and the MV and MH scores

\begin{tabular}{lll}
\hline $\begin{array}{l}\text { Visual acuity } \\
\text { (logMAR) }\end{array}$ & $\begin{array}{l}\text { MV } \\
\text { score }\end{array}$ & $\begin{array}{l}\text { MH } \\
\text { score }\end{array}$ \\
\hline Pre & $r=0.03$ & $r=0.1$ I \\
& $P=0.92$ & $P=0.73$ \\
Post I month & $r=0.38$ & $r=0.36$ \\
& $P=0.22$ & $P=0.25$ \\
Post 3 months & $r=0.53$ & $r=0.45$ \\
Post 6 months & $P=0.08$ & $P=0.14$ \\
& $r=0.20$ & $r=0.20$ \\
& $P=0.54$ & $P=0.53$ \\
\hline
\end{tabular}

Notes: There were no significant correlations between BCVA and MV and $\mathrm{MH}$ scores before surgery $(r=0.05, P>0.05$ for MV; $r=0.006, P>0.05$ for MH; Spearman rank correlation coefficient) and at 6 months after surgery $(r=0.21, P>0.1$ for MV; $r=0.35, P>0.1$ for $M H)$. However, there were significant correlations between $B C V A$ and $M V$ and $M H$ scores at I month after surgery $(r=0.5, P<0.05$ for $M V$; $r=0.5, P<0.05$ for $\mathrm{MH}$ ) and at 3 months after surgery $(r=0.6, P<0.0$ l for $M V ; r=0.49$, $P<0.05$ for $\mathrm{MH}$ ).

Abbreviations: BCVA, best-corrected visual acuity; MV, vertical metamorphopsia; $\mathrm{MH}$, horizontal metamorphopsia; $\log M A R$, logarithm of the minimum angle of resolution.
Another possible explanation would be the Fick illusion, ${ }^{26}$ whereby the MV score appears to be bigger than the MH score, even though they are the same in length. Because patients with a macular hole probably feel longer than the vertical length actually is, the MV score would become larger than the MH score.

In this study, there was no significant correlation between BCVA and the MV and MH scores at any assessment point. As previously reported, ${ }^{9,24}$ BCVA had neither significant correlation with the average metamorphopsia score nor with the MV or MH scores. Taken together, evaluating MV and $\mathrm{MH}$ scores in addition to BCVA can be an independent treatment outcome.

A previous study reported a significant correlation between the mean preoperative combined MH and MV scores and the fluid cuff only if the minimum diameter of the macular hole was less than $0.5 \mathrm{~mm} .{ }^{9}$ In another report, Sugiura et al ${ }^{24}$ recently quantified metamorphopsia in the vertical and horizontal directions in patients with macular hole and suggested that mean postoperative metamorphopsia scores were significantly correlated with the preoperative base diameters 
of the macular hole, the length of the defect in the external limiting membrane, and the area of the intraretinal cyst within the fluid cuff, by using type $1 \mathrm{M}-\mathrm{CHARTS} .{ }^{24}$ However, there were no significant correlations between $\mathrm{MV}$ or $\mathrm{MH}$ scores and the preoperative OCT parameters in this study.

The discrepancy between our results and those in the previous studies may reflect a difference in the average minimum diameter of the macular hole in different study populations. The proportion of patients with a minimum macular hole diameter $\geq 0.5 \mathrm{~mm}$ was $\sim 70 \%$ in our study population. Another possible explanation could be that we evaluated metamorphopsia scores using type 2 M-CHARTS and not the type 1 version, which was used in one of the previous studies. ${ }^{24}$ If type $1 \mathrm{M}$-CHARTS is used to detect metamorphopsia in patients with a macular hole, MV and $\mathrm{MH}$ scores cannot be accurately measured if the scotoma overlaps the center line of the M-CHARTS. In addition, the distance between the two lines of M-CHARTS is $10.48 \mathrm{~mm}$, and large scotoma did not influence the result of $\mathrm{MV}$ and $\mathrm{MH}$ scores in this study.

This study has some limitations, in particular its relatively small sample size and short follow-up duration. The area of ILM peeling might show positive correlation with the M-score. Future studies should include larger samples, longer durations of follow-up, and more detailed OCT analysis.

\section{Conclusion}

There was no significant correlation between BCVA and the MV and MH scores. The satisfaction of the patients with a macular hole after surgery cannot be necessarily measured by BCVA alone. Therefore, evaluating both the $\mathrm{MH}$ and $\mathrm{MV}$ scores in addition to BCVA can be an independent treatment outcome.

\section{Acknowledgments}

We thank Drs Yedi Zhou and Yoshiyuki Kobayashi for their fruitful discussions. The abstract of this paper was presented at the ARVO 2016 annual meeting as a poster presentation.

\section{Disclosure}

The authors report no conflicts of interest in this work.

\section{References}

1. Steel DH, Lotery AJ. Idiopathic vitreomacular traction and macular hole: a comprehensive review of pathophysiology, diagnosis, and treatment. Eye (Lond). 2013;27(suppl 1):S1-S21.

2. Kelly NE, Wende RT. Vitreous surgery for idiopathic macular holes. Results of a pilot study. Arch Ophthalmol. 1991;109(5):654-659.
3. Lois N, Burr J, Norrie J, et al; Full-thickness Macular Hole and Internal Limiting Membrane Peeling Study (FILMS) Group. Internal limiting membrane peeling versus no peeling for idiopathic fullthickness macular hole: a pragmatic randomized controlled trial. Invest Ophthalmol Vis Sci. 2011;52(3):1586-1592.

4. Hikichi T, Kosaka S, Takami K, et al. 23- and 20-gauge vitrectomy with air tamponade with combined phacoemulsification for idiopathic macular hole: a single-surgeon study. Am J Ophthalmol. 2011;152(1): 114-121.

5. Park DW, Sipperley JO, Sneed SR, Dugel PU, Jacobsen J. Macular hole surgery with internal-limiting membrane peeling and intravitreous air. Ophthalmology. 1999;106(7):1392-1397; discussion 1397-1398.

6. Gandorfer A, Messmer EM, Ulbig MW, Kampik A. Indocyanine green selectively stains the internal limiting membrane. Am J Ophthalmol. 2001;131(3):387-388.

7. Mochizuki N, Yamamoto T, Enaida H, Ishibashi T, Yamashita H. Longterm outcomes of 3 surgical adjuvants used for internal limiting membrane peeling in idiopathic macular hole surgery. Jpn J Ophthalmol. 2014;58(6):455-461.

8. Nakazawa M, Terasaki H, Yamashita T, Uemura A, Sakamoto T. Changes in visual field defects during 10-year follow-up for indocyanine green-assisted macular hole surgery. Jpn J Ophthalmol. 2016;60(5): 383-387.

9. Arimura E, Matsumoto C, Okuyama S, Takada S, Hashimoto S, Shimomura Y. Quantification of metamorphopsia in a macular hole patient using M-CHARTS. Acta Ophthalmol Scand. 2007;85(1):55-59.

10. Saito Y, Hirata Y, Hayashi A, Fujikado T, Ohji M, Tano Y. The visual performance and metamorphopsia of patients with macular holes. Arch Ophthalmol. 2000;118(1):41-46.

11. Krøyer K, Christensen U, Larsen M, la Cour M. Quantification of metamorphopsia in patients with macular hole. Invest Ophthalmol Vis Sci. 2008;49(9):3741-3746.

12. Krøyer K, Christensen U, la Cour M, Larsen M. Metamorphopsia assessment before and after vitrectomy for macular hole. Invest Ophthalmol Vis Sci. 2009;50(12):5511-5515.

13. Kim JH, Kang SW, Park DY, Kim SJ, Ha HS. Asymmetric elongation of foveal tissue after macular hole surgery and its impact on metamorphopsia. Ophthalmology. 2012;119(10):2133-2140.

14. Amsler M. L'Examen qualitatif de la fonction maculaire. [Qualitative review of macular function]. Ophthalmologica. 1947;114:248-261. French.

15. Amsler M. Earliest symptoms of diseases of the macula. Br JOphthalmol. 1953;37(9):521-537.

16. Watanabe A, Arimoto S, Nishi O. Correlation between metamorphopsia and epiretinal membrane optical coherence tomography findings. Ophthalmology. 2009;116(9):1788-1793.

17. Matsumoto C, Arimura E, Hashimoto S, Takada S, Okuyama S, Shimomura Y. A new method for quantification of metamorphopsia using M-CHARTS. Rinsho Ganka. 2000;54:373-377.

18. Arimura E, Matsumoto C, Okuyama S, Takada S, Hashimoto S, Shimomura Y. Retinal contraction and metamorphopsia scores in eyes with idiopathic epiretinal membrane. Invest Ophthalmol Vis Sci. 2005;46(8):2961-2966.

19. Okamoto F, Okamoto Y, Hiraoka T, Oshika T. Effect of vitrectomy for epiretinal membrane on visual function and vision-related quality of life. Am J Ophthalmol. 2009;147(5):869-874.

20. Okamoto F, Okamoto Y, Fukuda S, Hiraoka T, Oshika T. Visionrelated quality of life and visual function after vitrectomy for various vitreoretinal disorders. Invest Ophthalmol Vis Sci. 2010;51(2): 744-751.

21. Kinoshita T, Imaizumi H, Miyamoto H, et al. Changes in metamorphopsia in daily life after successful epiretinal membrane surgery and correlation with M-CHARTS score. Clin Ophthalmol. 2015;4(9): 225-233.

22. Arndt C, Rebollo O, Séguinet S, Debruyne P, Caputo G. Quantification of metamorphopsia in patients with epiretinal membranes before and after surgery. Graefes Arch Clin Exp Ophthalmol. 2007;245(8):1123-1129. 
23. Matsumoto C, Arimura E, Hashimoto S, Takada S, Okuyama S, Shimomura Y. Quantification of metamorphopsia in patients with epiretinal membranes. Invest Ophthalmol Vis Sci. 2003;44(9):4012-4016.

24. Sugiura Y, Okamoto F, Okamoto Y, Hiraoka T, Oshika T. Relationship between metamorphopsia and intraretinal cysts within the fluid cuff after surgery for idiopathic macular hole. Retina. 2017;37(1):70-75.
25. Krasnicki P, Dmuchowska DA, Pawluczuk B, Proniewska-Skretek E, Mariak Z. Metamorphopsia before and after full-thickness macular hole surgery. Adv Med Sci. 2015;60(1):162-166.

26. Wade NJ. Geometrical optical illusionists. Perception. 2014;43(9): 846-868. 


\section{Supplementary material}

Table SI Relationship between preoperative OCT parameters and MV and MH scores at all assessment times

\begin{tabular}{|c|c|c|c|c|c|c|c|c|}
\hline $\begin{array}{l}\text { Preoperative } \\
\text { OCT } \\
\text { parameters }\end{array}$ & $\begin{array}{l}\text { Minimum } \\
\text { diameters } \\
\text { (vertical) }\end{array}$ & $\begin{array}{l}\text { Minimum } \\
\text { diameters } \\
\text { (horizontal) }\end{array}$ & $\begin{array}{l}\text { Average } \\
\text { angle } \\
\text { (vertical) }\end{array}$ & $\begin{array}{l}\text { Average } \\
\text { angle } \\
\text { (horizontal) }\end{array}$ & $\begin{array}{l}\text { Base } \\
\text { diameters } \\
\text { (vertical) }\end{array}$ & $\begin{array}{l}\text { Base } \\
\text { diameters } \\
\text { (horizontal) }\end{array}$ & $\begin{array}{l}\text { Fluid cuff } \\
\text { (vertical) }\end{array}$ & $\begin{array}{l}\text { Fluid cuff } \\
\text { (horizontal) }\end{array}$ \\
\hline \multicolumn{9}{|c|}{ MV score/MH score } \\
\hline Pre & $0.39 / 0.42$ & $0.44 / 0.81$ & $0.37 / 0.77$ & $0.97 / 0.63$ & $0.4 \mathrm{I} / 0.46$ & $0.36 / 0.76$ & $0.58 / 0.58$ & $0.70 / 0.19$ \\
\hline Post I month & $0.51 / 0.99$ & $0.59 / 0.83$ & $0.55 / 0.59$ & $1.00 / 0.6 \mid$ & $0.70 / 0.70$ & $0.96 / 0.88$ & $0.30 / 0.65$ & $0.97 / 0.79$ \\
\hline Post 3 months & $0.83 / 0.56$ & $0.8 \mathrm{I} / 0.56$ & $0.73 / 0.48$ & $0.47 / 0.97$ & $0.88 / 0.73$ & $0.61 / 0.95$ & $0.50 / 0.77$ & $0.93 / 0.59$ \\
\hline Post 6 months & $0.67 / 0.90$ & $0.65 / 0.92$ & $0.91 / 0.24$ & $0.99 / 0.43$ & $0.49 / 0.60$ & $0.49 / 0.65$ & $0.73 / 0.48$ & $0.37 / 0.61$ \\
\hline
\end{tabular}

Notes: The preoperative OCT parameters include minimum diameters, average angle, base diameters, and fluid cuff in both the vertical and horizontal directions. There were no significant correlations between the preoperative OCT parameters and the MV and MH scores at any assessment time (Spearman rank correlation coefficient). Abbreviations: OCT, optical coherence tomography; MV, vertical metamorphopsia; $\mathrm{MH}$, horizontal metamorphopsia.

\section{Publish your work in this journal}

Clinical Ophthalmology is an international, peer-reviewed journal covering all subspecialties within ophthalmology. Key topics include: Optometry; Visual science; Pharmacology and drug therapy in eye diseases; Basic Sciences; Primary and Secondary eye care; Patient Safety and Quality of Care Improvements. This journal is indexed on
PubMed Central and CAS, and is the official journal of The Society of Clinical Ophthalmology (SCO). The manuscript management system is completely online and includes a very quick and fair peer-review system, which is all easy to use. Visit http://www.dovepress.com/ testimonials.php to read real quotes from published authors. 